\title{
Scientific Inquiry on Various Styles of Yoga for Revitalizing Psychological Health
}

\author{
Kavitha Palaniappan* \\ UON Singapore, Singapore
}

Submission: February 15, 2018; Published: March 22, 2018

*Corresponding author: Kavitha Palaniappan, UON Singapore (a wholly owned entity of the University of Newcastle, Australia), 6 Temasek Boulevard, \#10-02/03, Suntec Tower 4, Singapore, Email: Kavitha.Palaniappan@newcastle.edu.au

Abstract

Yoga is an ancient discipline designed to bring balance and health to the physical, mental, emotional and spiritual dimensions of the individual. Yoga is often depicted metaphorically as a tree comprising of eight branches or aspects: yama, niyama, asana, pranayama, pratyahara, dharana, dhyana and samadhi. Each branch is connected with the whole, in the same way that bodily limbs are all connected. All these work together and they are not stages to be achieved one after another. Even though Yoga includes all eight aspects, it is most often understood to be a program of physical exercises (asanas) and breathing exercises (pranayama) and in some instances includes meditation (dhyana). There are six major styles of yoga that are practiced and popular worldwide and they are Hatha, Anasara, Iyengar, Bikram, Kundalini and Ashtanga. Studies have shown that irrespective of the style of yoga that is practiced, regular yoga practice revitalizes psychological health by reducing stress, anxiety and depression. This study aims to elucidate the scientific inquiry behind the various styles of yoga in revitalizing psychological health. Keywords: Styles of yoga; Postures; Meditation; Mindful breathing; Stress; Anxiety; Depression

\section{Introduction}

As Madanmohan [1] mentions, the word "Yoga" means union of our individual consciousness with the Universal Divine Consciousness in a super-conscious state known as "Samadhi". Yoga is an ancient therapeutic practice and is based on Patanjali yoga sutras [2]. It basically consists of yogic practices based on ancient yoga texts and addresses the mind and body in a holistic way [3]. However, in the western context, the word yoga is more often associated to only postures called asanas that include breath control and meditation.

Quality of life is usually associated to the physical wellbeing of individuals and several studies have been done to indicate that chronic illnesses lower the quality of life. In one study, the quality of life of patients was lower than the general population both before admission and after discharge from the hospital [4]. On the other hand, anxiety, depression, fatigue and stress have all been associated either individually or as a whole to several diseases. Hence, not only physical factors, but also psychological and social health factors need to be incorporated in the concept of general well-being [5]. Yoga, with a marked increase in worldwide popularity is being researched to improve the quality of life. Several studies have shown that physical wellbeing has shown significant improvement with regular practice of yoga, immaterial of which style that is being practiced. In one randomized controlled trial for participants with non-specific chronic low back pain, yoga was found to reduce pain intensity by $64 \%$, functional disability by $77 \%$ and pain medication usage by $88 \%$ [6].

There are also a few studies to indicate the effectiveness of yoga on improving the psychological health as well. This study is to provide scientific inquiry by reviewing the effectiveness of different styles of yoga in resolving certain psychosocial illnesses such as anxiety, depression, fatigue and stress.

\section{What is Yoga?}

The word "Yoga" comes from Sanskrit and it means to yoke or to join together the mind, body and spirit. According to Yoga Sutras written by the Indian scholar and physician Patanjali in 3000 BC, the 'Eight Limbs of Yoga' include moral restraints in terms of kindness, truthfulness, non-stealing, moderation of vital energies and generosity (yamas), observance of purity, contentment, austerity, self-study and surrendering ego (niyamas), postures (asanas), mindful breathing (pranayama), withdrawal of the senses to the mind (pratyahara), concentration (dharana), meditation (dhyana) and attaining pure bliss through tranquility, fulfillment and spiritual illumination (Samadhi) [7]. These eight stages form a cumulative series that embody ethical principles of behavior and meditative states [8].

However, as per Iyengar [9], Yoga is a quest for the soul and he basically divides the eight limbs of Yoga into outward quests, inner quests and the innermost quests that lead one in 
the pursuit of their soul. The first three stages of the outward quests are to first follow universal ethical principles such as non-violence, truth, non-stealing, continence and non-coveting, followed by being bound by rules of conduct for individual discipline such as cleanliness, contentment and austerity in terms of body, speech and mind and then comes Asanas or postures which are expected to keep the body healthy and strong. The next two stages of the inner quests include the act of regulating one's breathing, commonly known as "Pranayama" and "Pratyahara", which is to bring all the senses under one's control. The next three stages, namely Dharana (concentration), Dhyana (Meditation) and Samadhi (Body at rest and Mind fully conscious and alert) are the innermost quests that are generally not easy to achieve and come with regular and systematic practice. B.K.S. Iyengar indicates that with uninterrupted flow of concentration (Dharana), one can reach the stage of meditation (Dhyana) where one's body, breathe, senses, mind, reason and ego are all integrated.

\section{Styles of Yoga}

There are six styles of yoga that are popular today and they are Hatha, Anasara, Iyengar, Bikram, Kundalini and Ashtanga. Hatha (sun/moon) yoga is the one that is most commonly practiced and it basically combines poses with breathing techniques. This style is said to relax and restore the body by developing flexibility and balance. Anasara yoga is characterized by free-flowing movements usually called Vinyasa and this style is used to develop strength, flexibility and balance. Iyengar yoga is the one that uses props to hold poses longer and is known for strengthening muscles and supporting the joints. Bikram yoga is the hot yoga which is practiced in a high temperature room in the range of 105 degrees Fahrenheit and about 40\% humidity [10]. This style involves a series of 26 poses to build flexibility. Kundalini yoga is mainly to calm the mind and energize the body. This style of yoga gives a more spiritual experience [11]. The Ashtanga yoga is the power yoga which includes poses that could be physically challenging and is mainly practiced by experienced yoga practitioners.

\section{States of Mind for Good Psychological Health}

The five states of mind that one goes through during the process of concentration clearly explains how one can achieve meditation and these can also throw some light on how Yoga can be used for the treatment of mental illnesses such as stress, anxiety and depression. When one tries to attempt meditation, usually, the first state of mind is that of thoughts being scattered and disarrayed and slowly the mind goes into the next state where it is agitated and distracted. On calming the mind, it then becomes dull and not capable of thinking anything which is the third state. The fourth state is the one where the mind slowly starts to concentrate and focus on just one point. At this state, it is possible to divert the mind towards both positivity and negativity and when one is capable of diverting it to positivity, then the last state of mind, where the mind, intellect and ego are all restrained is said to have been achieved [2].

\section{Scientific Inquiry on Yoga for Better Psychological Health}

Most people practice yoga for its health benefits and the elementary hatha yoga courses concentrate mainly on physical exercies consisting of various postures (asanas) and breathing techniques. A growing body of research evidence supports the belief that certain yoga techniques may improve physical and mental health through down-regulation of both the hypothalamo-pituitary adrenal (HPA) axis and the sympathetic nervous system responses to stress [12]. Studies have also established that short-term yoga practice is capable of deviating both sympathetic and parasympathetic indices towards more normal reference values, thereby normalizing the autonomic nervious system [13]. Several studies have shown that yoga has immediate psychological effects such as decreasing anxiety [1416] increasing feelings of emotional, social and spiritual wellbeing [17].

Regular practice of yoga is also said to decrease salivary cortisol levels [16], the hormones responsible for stress and depression, blood glucose [18] and plasma rennin levels [19], and the 24 hour urine nor-epinephrine and epinephrine levels [20]. Several studies have noted that yoga is capable of decreasing both the systolic as well as diastolic blood pressures and the heart rate [21-23]. Even though the exact mechanism of action in such cases is unknown, the hypothesis is that yogic physical exercises cause a shift towards parasympathetic nervious system dominance, possibly via direct vagal stimulation [23]. Another study found that when depressed patients underwent a yoga intervention treatment for about 8 weeks, showed a reduction in low-frequency heart rate variability, which is basically a sign of sympathetic nervous system activation [24].

Dunn's study reveals that Hatha yoga improves mood disorders, increases overall wellbeing and decreases perceived stress by regulating cortisol and decreasing the basal metabolic rate (BMR). A reduced BMR improves cardio-respiration and decreases oxidative stress markers [25]. A controlled clinical trial indicated that Hatha yoga minimizes stress by reducing inflammatory and endocrine responses [26]. Yet another study pointed out that yoga decreases the salivary cortisol levels which in turn decreased perceived stress and improved overall wellbeing and the quality of life [27].

Depressive symptomatology has been found to be reduced by increased levels of gamma-aminobutyric acid (GABA), vagus nerve stimulation through neurotransmitters and decreased cortisol levels [28] by regular yoga practice. Cortical and HPA axis interactions on cellular, neuro-humoral and immune system have been attributed to stress reduction in a group of yoga practitioners [29]. Yoga along with pranayama is said to regulate the hormones which in turn enhances mood [30]. 


\section{Journal of Yoga and Physiotherapy}

\section{Conclusion}

There is substantial evidence in the literature to prove that Hatha yoga is beneficial for various health conditions including psychological issues. However, the scientific inquiry behind most of the suggested remedies for the other styles of yoga is yet to be investigated and established. Even though the term "Yoga" is commonly used to refer to Asanas, it is implicit to understand that Pranayama (breathing regulation) and Meditation (Dhyana) are actually two limbs of the eight limbs of Yoga and they all need to be included under the term "Yoga". Different styles of yoga along with the other limbs of Yoga needs to be studied and their scientific inquiry also needs to be established.

\section{References}

1. Madanmohan (2007) Role of yoga and ayurveda in cardiovascular disease.

2. Iyengar BKS (2012) Heart of the yoga sūtras: the definitive guide to the philosophy of yoga, HarperCollins Publishers L.L.C, USA.

3. Udupa KN,Prasad RC (1985) Stress and its management by yoga, Motilal Banarsidass, Inida, p. 395.

4. Dowdy DW, Eid MP, Sedrakyan A, Mendez Tellez PA, Pronovost PJ, et al. (2005) Quality of life in adult survivors of critical illness: a systematic review of the literature. Intensive Care Med 31(5): 611-620.

5. Testa MA, Simonson DC (1996) Assessment of Quality-of-Life Outcomes. N Engl J Med 334(13): 835-840.

6. Williams KA, Petronis J, Smith D, Goodrich D, Wu J, et al. (2005) Effect of lyengar yoga therapy for chronic low back pain. Pain 115(1-2): 107117

7. Freeman LW (2009) Mosby's complementary \& alternative medicine: a research-based approach. ( ${ }^{\text {rd }}$ edn), Edinburgh: Mosby, USA, p. 608.

8. Desikachar TKV (1995) The heart of yoga: developing a personal practice. In: Inner Traditions International, USA, p.244.

9. Iyengar BKS, Iyengar BKS (1997) The illustrated light on yoga: yoga dipika, Harper Collins Publishers, India, pp. 1-179.

10. Kudesia RS, Bianchi MT (2012) Decreased Nocturnal Awakenings in Young Adults Performing Bikram Yoga: A Low-Constraint Home Sleep Monitoring Study. ISRN Neurol 2012: 153745.

11. Shannahoff Khalsa DS (2004) An introduction to Kundalini yoga meditation techniques that are specific for the treatment of psychiatric disorders. J Altern Complement Med 10(1): 91-101.

12. Kirkwood G, Rampes H, Tuffrey V, Richardson J, Pilkington K (2005) Yoga for anxiety: a systematic review of the research evidence. $\mathrm{Br} \mathrm{J}$ Sports Med 39(12): 884-891.

13. Pilkington K, Kirkwood G, Rampes H, Richardson J (2005) Yoga for depression: the research evidence. J Affect Disord 89(1-3): 13-24.

14. Gupta N, Khera S, Vempati RP, Sharma R, Bijlani RL (2006) Effect of yoga based lifestyle intervention on state and trait anxiety. Indian J Physiol Pharmacol 50(1): 41-47.
15. Telles S, Naveen KV, Dash M, Deginal R, Manjunath NK (2006) Effect of yoga on self-rated visual discomfort in computer users. Head Face Med 2: 46.

16. West J, Otte C, Geher K, Johnson J, Mohr DC (2004) Effects of Hatha yoga and African dance on perceived stress, affect, and salivary cortisol. Ann Behav Med 28(2): 114-118.

17. Moadel AB, Shah C, Wylie Rosett J, Harris MS, Patel SR, et al. (2007) Randomized controlled trial of yoga among a multiethnic sample of breast cancer patients: effects on quality of life. J Clin Oncol 25(28): 4387-4395.

18. Khatri D, Mathur KC, Gahlot S, Jain S, Agrawal RP (2007) Effects of yoga and meditation on clinical and biochemical parameters of metabolic syndrome. Diabetes Res Clin Pract 78(3): e9-e10.

19. Gokal R, Shillito L, Maharaj SR (2007) Positive impact of yoga and pranayam on obesity, hypertension, blood sugar, and cholesterol: a pilot assessment. J Altern Complement Med 13(10): 1056-1057.

20. Selvamurthy W, Sridharan K, Ray US, Tiwary RS, Hegde KS, et al. (1998) A new physiological approach to control essential hypertension. Indian J Physiol Pharmacol 42(2): 205-213.

21. McCaffrey R, Ruknui P, Hatthakit U, Kasetsomboon P (2005) The effects of yoga on hypertensive persons in Thailand. Holist Nurs Pract 19(4) 173-180.

22. Damodaran A, Malathi A, Patil N, Shah N, Suryavansihi, et al. (2002) Therapeutic potential of yoga practices in modifying cardiovascular risk profile in middle aged men and women. J Assoc Physicians India 50(5): 633-640

23. Innes KE, Bourguignon C, Taylor AG (2005) Risk indices associated with the insulin resistance syndrome, cardiovascular disease, and possible protection with yoga: a systematic review. J Am Board Fam Pract 18(6): 491-519.

24. Shapiro D, Cook IA, Davydov DM, Ottaviani C, Leuchter AF, et al. (2007) Yoga as a complementary treatment of depression: effects of traits and moods on treatment outcome. Evid Based Complement Altern Med 4(4): 493-502.

25. Dunn KD (2008) A review of the literature examining the physiological processes underlying the therapeutic benefits of Hatha yoga. Adv Mind Body Med 23(3): 10-8.

26. Kiecolt Glaser JK, Christian L, Preston H, Houts CR, Malarkey WB, et al. (2010) Stress, inflammation, and yoga practice. Psychosom Med 72(2): 113-121.

27. Field T (2011) Yoga clinical research review. Complement Ther Clin Pract 17(1): 1-8.

28. Kinser PA, Goehler LE, Taylor AG (2012) How might yoga help depression? A neurobiological perspective. Explore (NY) 8(2): 118126.

29. Kulkarni DD, Bera TK (2009) Yogic exercises and health--a psychoneuro immunological approach. Indian J Physiol Pharmacol 53(1): $3-15$.

30. Sengupta P (2012) Health Impacts of Yoga and Pranayama: A State-ofthe-Art Review. Int J Prev Med 3(7): 444-458. 
This work is licensed under Creative Commons Attribution 4.0 License

DOI: 10.19080/JYP.2018.04.555638

\footnotetext{
Your next submission with Juniper Publishers will reach you the below assets

- Quality Editorial service

- Swift Peer Review

- Reprints availability

- E-prints Service

- Manuscript Podcast for convenient understanding

- Global attainment for your research

- Manuscript accessibility in different formats

( Pdf, E-pub, Full Text, Audio)

- Unceasing customer service

Track the below URL for one-step submission https://juniperpublishers.com/online-submission.php
} 